\title{
Flexible Cystoscopy a Valuable Diagnostic Lool for Lower Urinary Tract Pathology
}

\author{
Md. Rokonuzzaman Khan ${ }^{1}$, Fazal Naser ${ }^{2}$, Moazzam Hossain ${ }^{3}$, Mostafizur Rahman ${ }^{4}$
}

Received: 08 - 06 - 2020

Accepted: 05 - 08 - 2020

Conflicts of interest: None

Keywords: Flexible cystoscopy, lower urinary tract

\begin{abstract}
Objective: To assess the role of flexible cystoscopy in the diagnosis of lower urinary tract pathology and its suitability as a routine diagnostic protocol in outdoor patients.

Methods: The cross sectional study was conducted at the advanced centre of kidney diseases and urology, Dhaka central international medical college, Dhaka from Jan 2016 to jan2019. All adult patients presenting with lower urinary symptoms to outdoor department were included. Flexible Cystoscopy was performed as a outdoor based procedure without sedation.
\end{abstract}

Results: Of the 249 patients in the study,198(79\%) were male and 51(21\%) were female. Lower urinary tract pathologies were found in $192(72 \%)$ patients. The most common pathology among males was enlarged prostate $56(31 \%)$ patients. Urethral stricture, bladder neck high were found 23(11\%),21(10\%) respectively. Among females, urethral stenosis was the most common pathology in 23(32\%) patients. Transitional cell carcinoma was seen in 11(4.4\%) patients having hematuria with inconclusive ultrasound and intravenous urography. All patients tolerated the procedure well with no procedure related complaints.

Conclusion: Flexible cystoscopy is an effective, well tolerated and easy way of detecting lower urinary tract pathologies. It can alter the management as well as support the diagnosis and management. It is also helpful in routine surveillance of bladder tumours of low grade and low stage. Flexible cystoscopy should therefore be used as routine diagnostic protocol in outdoor practice.

\section{Introduction:}

Endoscopic examination of the bladder, lower urinary tract and prostate gland is a time- honoured investigation for thorough evaluation ${ }^{1}$.It can also be used to collect urine sample, perform biopsies, removal of small stones, and D-J stent.Endoscopy of the urinary tract remains the cornerstone of urological therapy.
Over the years, continued refinement of the endoscopic instrument has permitted a progressive increase in the number and methods of their application. Cystoscopy under local anaesthesia has been established as an office-based procedure since 1980s. ${ }^{2}$ The development of the smaller diameter, flexible endoscopes represent the greatest advance in urological endoscopy. ${ }^{3}$

1. Assistant Professor, Urology, MARMCH, Dinajpur.

2. Associate Professor, Urology, ShSMCH. Dhaka

3. Assistant Professor, Urology, Sheikh Abu Naser Specialized Hospital, Khulna.

4. Assistant Professor, Urology, KYAMCH, Serajganj.

Correspondences: Dr. Md. Rokonuzzaman Khan, Assist. Professor, Urology, M Abdur Rahim Medical College Hospital (MARMC), Dinajpur5200, E-mail: dr.rokon77@gmail.com 
Endoscopic methods for diagnosis and treatment of urological diseases, the characteristics of their value and their importance for modern urology become evident by the fact that by means of these methods, the basis of which was created 100 yrs ago with the introduction of cystoscopy. ${ }^{4}$ Most evidence suggests that outpatient flexible cystoscopy is associated with minimum complications. ${ }^{5}$ The objective of the current study was to assess the role of flexible cystoscopy in the diagnosis of lower urinary tract pathologies and whether it is valuable enough to be used as routine diagnostic protocol in outdoor practice.

\section{Methods:}

The study was conducted at the advanced centre of kidney diseases and urology, Dhaka central international medical college, Dhaka from Jan 2016 to jan2019. All adult patients presenting with lower urinary symptoms to outdoor department were included. X-ray of KUB region was done in all patients and those having positive findings were excluded. History was taken in the outpatient department and patients were counseled about the procedure. Ing amikacin $500 \mathrm{mg}$ i/v stat was given in the morning on the day of flexible cystoscopy which was performed as a outdoor based procedure without sedation and $2 \%$ lignocaine gel was used as the topical local anaesthetic agent.

\section{Results:}

Of the 249 patients in the study, flexible cystoscopies performed,198(79\%) were male and $51(21 \%)$ were female. Lower urinary tract pathologies were found in $192(72 \%)$ patients of which $150(78.12 \%)$ male and $42(22 \%)$ female. In these patients, X-ray KUB had no positive finding. The most common pathology among

Table-I : Pathologies detected on flexible cystoscopy.

\begin{tabular}{lccc}
\hline Pathology & Frequency & $\begin{array}{c}\text { Percentage } \\
\text { from total } \\
\text { sample }\end{array}$ & $\begin{array}{c}\text { Percentage } \\
\text { from positive } \\
\text { pathological } \\
\text { findings }\end{array}$ \\
\hline Enlarged prostate & 56 & $28.28 \%$ & $37 \%$ \\
Urethral stricture & 23 & $11 \%$ & $15 \%$ \\
Bladder neck high & 21 & $10 \%$ & $14 \%$ \\
$\begin{array}{l}\text { Female urethral } \\
\text { stenosis }\end{array}$ & 13 & $25 \%$ & $30 \%$ \\
Transitional cell & 11 & $4.4 \%$ & $5.5 \%$ \\
carcinoma & & & \\
\hline
\end{tabular}

males was enlarged prostate $56(31 \%)$ patients. Urethral stricture, bladder neck high were found $23(11 \%)$, $21(10 \%)$ respectively. Among females, urethral stenosis was the most common pathology in $13(32 \%)$ patients. Transitional cell carcinoma was seen in $11(4.4 \%)$ patients having haematuria with inconclusive ultrasound and intravenous urography. .All patients tolerated the procedure well with no procedure related complaints.

\section{Discussion:}

The introduction of high- quality flexible cystoscope has allowed comfortable examination on outdoor basis, using local anaesthetic gel to aid introduction of instrument. ${ }^{6,7}$ The use of local anaesthetic has been questioned and there is little evidence that gel insertion decreases pain sensation, especially in females. ${ }^{8}$ There has been a considerable increase in the use of flexible cystoscopy and this has led to the criticism that this procedure is being overuse with no management benefit. ${ }^{9}$ Lower urinary tract pathologies are grossly divided into two categories, i,e. pathologies related to urinary bladder and pathologies related to urethra. Urethral pathologies most of the time present with symptoms of bladder outlet obstruction and are sometimes not diagnosed on ultrasonography alone. Both pathologies of urinary bladder and urethra can easily be diagnosed by cystoscopy alone. Cystoscopy alone or in combination with excretory urography, or intravenous urography (IVU), is one of the most significant diagnostic tools in young patients with microscopic haematuria. ${ }^{10-12}$ Haematuria was the presenting complaints in 11 patients in our study.With the use of urethrocystoscopy, there is rapid completion of diagnostic workup, and operations for surgical conditions can be scheduled more promptly. The patients included in our study were all those who presented with lower urinary tract symptoms only and who had no pathology detected on $x$-ray KUB.Instead of waiting for ultrasonography, flexible cystoscopic was performed. There was detection of pathologies in $72 \%$ of cases.Another study ${ }^{9}$ conducted with flexible cystoscopy in 1390 patients with positive findings in $46.14 \%$.In our study enlarged prostate was found in $31 \%$ patients. Flexible cystoscopy in these cases ruled out any other pathology in bladder like small growth and carcinoma in situ(cis), which is not detected on ultrasonography. Urethral stricture $23 \%$,bladder neck high $21 \%$,Bladder stone $2 \%$.Our findings correlate with a study ${ }^{13}$ which detected prostatic enlargement in $31 \%$,urethral stricture in $23 \%$ patients. Both flexible and 
rigid cysto-urethroscopy are routinely used in surveillance of transitional cell carcinoma bladder tumour. ${ }^{14}$ Urethrocystoscopy is the reference standard diagnostic test in the follow-up of patients with superficial bladder cancer, and flexible cystoscopy is frequently used for follow-up of bladder carcinomas. ${ }^{15,16}$ Although by combining ultrasonography and flexible cystoscopy most carcinomas can be diagnosed and abnormalities detected, but there would be a delay in diagnosis due to overburden radiology department ${ }^{11}$. Bladder growth was detected in $11(4.4 \%)$ cases with haematuria.one study ${ }^{9}$ showed cancer detection rate $6.10 \%$.Early diagnosis of patients with bladder growth helped in early management as these patients did not have to wait for ultrasonography. Early resection of tumour was done on the next available day.New advancements have made cystoscopy not only a good diagnostic,but a therapeutic tool as well.

\section{Conclusion:}

Flexible cystoscopy is an effective, well tolerated and easy way of detecting lower urinary tract pathologies.It can alter the management as well as support the diagnosis and management.It is also helpful in routine surveillance of bladder tumours of low grade and low stage. Flexible cystoscopy should therefore be used as routine diagnostic protocol in outdoor practice.

\section{References}

1. Patel AR. Jones JR, Angie S, Babineau O. Office based flexible cystoscopy may be less painful for men allowed to view the procedure. J Urol 2997;177;1843-5.

2. Kadi N, Menezes P.ABC of flexible cystoscopy for junior trainee and general practitioner. Int J Gen Med 2011;4:593-6.

3. Rivas DA. Chancellor MB. Flexible cystoscopy in spinal cord injury. Review article.paraplegia. 1994;32:454-62.

4. Lopatkin NA, Shchabad AL. Cystoscopy and its importance in urology. Z Urol Nephr of 1979;72:517-22.

5. Kraklau DM, Wolf JS. Review of antibiotic prophylaxis recommendations for office-based urological procedures. Tech Urol 1999;5:123-8.
6. Young M, Martínez S, Del Rosario J, Anguizola C. [Bladder endoscopy (cystoscopy): indications and most frequent findings at the Metropolitan Hospital Complex of the Social Security Fund of Panama, 1997]. Rev Med Panama 1998; 23: 20-3.

7. Keoghane SR, Ritchie AW, Jones DJ. An audit of positive findings in flexible and rigid check cystoscopy. J R Army Med Corps 1999; 145: 143-4.

8. Adrian PM van der Meijden. Bladder cancer. BMJ 1998; 317: 1366-9.

9. Cohen BL, Rivera R, Barboglio P, Gousse A. Safety and tolerability of sedation-free flexible cystoscopy for intradetrusor botulinum toxin-A injection. J Urol 2007; 177: 1006-10; discussion 1010.

10. Quayle SS, Ames CD, Lieber D, Yan Y, Landman J. Comparison of optical resolution with digital and standard fiberoptic cystoscopes in an in-vitro model. Urology 2005; 66: 489-93.

11. Andonian S, Okeke Z, Smith AD. Digital ureteroscopy: the next step. J Endourol 2008; 22: 603-6.

12. Fraczyk L, Godfrey H, Feneley R. Flexible cystoscopy: outpatients or domiciliary? Br J Community Nurs 2002; 7: 69-74.

13. Young M,Martinez S,Del Rosario J,anguizola c.[bladder endoscopy(cystoscopy):indications and most frequent findings at the Metropolitan Hospital Complex of the social Security Fund of Panama,1997].RevMed Panama 1998;23:20-3.

14. Keoghane SR,RitchieAW,JonesDJ.An audit of positive findings in flexible and rigid check cystoscopy.J R Army Med corps 1999;145:143-4.

15. Adrian PM van der Meijden.Bladder cancer,BMJ 1998;317;1366-9.

16. Cohen BL,Rivera R,Barboglio P,Gousse A.Safety and tolerability of sedation-free flexible cystoscopy for intradetrusor botulinum toxin-A injection.JUrol 2007;177:1006-10; discussion 1010. 